\title{
Prediction of wood density breeding values of Pinus taeda elite parents from unbalanced data: A method for adjustment of site and age effects using common checklots
}

\author{
Fikret ISIK*, Bailian LI, Barry GoLDFARB, Steve MCKEAND \\ North Carolina State University, Department of Forestry and Environmental Resources, Campus Box 8002, Raleigh, NC 27695, USA
}

(Received 29 May 2007; accepted 29 January 2008)

\begin{abstract}
-
- Wood density of elite parents of loblolly pine (Pinus taeda L.) was investigated in 6 to 18 year-old progeny trials. The sampling was carried out separately in seven testing regions in the southeastern US. A checklot was the only connection between elite parents planted at different trials in a testing region.

- We used a data normalization method suggested for unbalanced designs in cDNA microarray experiments to remove confounding site and age effects using the checklot as a reference sample. Wood density breeding values of parents were predicted by fitting a linear mixed model to the normalized data.

- Using the reference samples to remove site and age effects appears to be an effective method for analysis of unbalanced progeny tests data. In general, wood density $\left(\mathrm{kg} / \mathrm{m}^{3}\right)$ decreased from coastal to inland plantings and from the southern to the northern planting. Considerable genetic variation for wood density was detected among these fast-growing elite parents in six of seven testing regions, with half-sib family mean heritabilities ranging from 0.71 to 0.97 within a testing region. With the exception of two regions, checklots were stable across trials in a region, based on regressing the checklot means on trial means.
\end{abstract}

loblolly pine / reference sample / data normalization / genetic variation / heritability

Résumé - Prédiction des valeurs de densité du bois pour la sélection de parents d'élite de Pinus taeda, à partir de données non équilibrées : une méthode d'ajustement des effets d'environnement et d'âge basée sur des lots de référence communs.

- La densité du bois de parents d'élite de Pinus taeda L. a été étudiée dans des essais de descendance âgés de 6 à 18 ans. L'échantillonnage a été mené à bonne fin séparément dans sept régions tests du Sud des États-Unis. Le lot a été le seul lien entre parents d'élite plantés dans différents essais dans la région de test.

- Nous avons utilisé une méthode de normalisation des données proposée pour des effectifs non équilibrés de puces à CDNA pour éliminer les effets confondus du site et de l'âge, en utilisant le lot comme échantillon de référence. Les valeurs de la densité du bois des parents ont été prédites par ajustement d'un modèle linéaire mixte aux données normalisées.

- Utiliser les échantillons références pour enlever les effets de site et de l'âge apparaît être une méthode efficace pour analyser les données non équilibrées d'un test de descendances. En général, la densité du bois $\left(\mathrm{kg} / \mathrm{m}^{3}\right)$ décroît depuis les plantations côtières jusqu'aux plantations des régions intérieures et depuis les plantations du sud jusqu'aux plantations plus au nord. Une variabilité génétique considérable de la densité du bois a été détectée entre ces parents à croissance rapide dans six des sept régions de test, avec des héritabilités moyennes variant de 0,71 à 0,97 dans une région de test. Sur la base d'une régression entre moyennes des lots de référence et moyennes des essais, il a été déterminé qu'à l'exception de deux régions, les lots ont été stables à travers les essais dans une région déterminée.

Pinus taeda / échantillon de référence / normalisation des données / variation génétique / héritabilité

\section{INTRODUCTION}

Forest tree improvement programs have had a considerable, positive impact on the productivity of plantation forestry around the world. In the Southeast USA, multiple cycles of breeding and selection, in combination with intensive silvicultural treatments, have resulted in substantial productivity improvements for Pinus taeda L. (loblolly pine) (Li et al., 1999). Pinus taeda is one of the most widely planted tree species in the world. In the southern USA alone, almost one billion genetically improved seedlings are planted every year (McKeand

*Corresponding author: fikret_isik@ncsu.edu et al., 2003). As is common in tree breeding programs, the emphasis in genetic improvement of $P$. taeda has largely been on growth rate, with additional attention given to bole straightness and fusiform rust disease (Cronartium quercuum (Berk) Miyabe ex Shirai f. sp. fusiforme) resistance.

Deployment of genetically superior trees and enhanced silvicultural practices has reduced the rotation ages for P. taeda. Wood produced from rapidly growing young plantations contains proportionally more juvenile wood, which has many undesirable characteristics as compared to mature wood (Megraw, 1985). The increase in juvenile wood from intensively managed pine plantations is mainly due to shorter 
rotation ages (Zobel and Sprague, 1998). Wood density, an important trait that affects pulp and paper yield and structural wood quality, is typically lower in juvenile wood. As a result, the quality of the wood produced in young plantations has raised concerns among the tree improvement and forest tree utilization communities. Including wood density in $P$. taeda improvement programs could potentially offset the decrease in density resulting from juvenile wood.

Wood density assessment on the large sample of trees necessary for tree breeding programs is time consuming and, can be prohibitively expensive. Several rapid wood density assessment methods, such as the Pilodyn (Cown, 1978) and the Resistograph (Isik and Li, 2003) have been explored for screening progeny trials for relative wood density. Low phenotypic correlations between wood density and Pilodyn values reported in some studies (Gough and Barnes, 1984) have discouraged tree breeders from further use of the tool. The Resistograph system explored by Isik and Li (2003) is a relatively new method and needs to be tested for different age groups and populations before further use. An alternative approach for screening tree breeding populations would be subsampling the populations, such as focusing on elite parents. One strategy for improving wood density in plantations would be to first select elite parents based on growth rate, disease resistance and bole straightness, and then screen these selections for wood density. Ultimately families and/or clones with high wood density could be multiplied to meet reforestation needs.

A large number of studies have been carried out to study variation and genetic control in wood density of $P$. taeda. Wood density based on breast-height wood cores for P. taeda ranged from 353 (Talbert et al., 1983) to $550\left(\mathrm{~kg} / \mathrm{m}^{3}\right)$ (Zobel and Talbert, 1984), depending on the populations studied. Jett et al. (1991) reported a range of 406 to $461 \mathrm{~kg} / \mathrm{m}^{3}$ wood density means from seven different test sites encompassing an area spanning the natural distribution range of the species. A trend has been noted for average wood density of natural and experimental populations of $P$. taeda, in which density generally decreases from the Coastal plains to the inland Piedmont and from the south to the north (Belonger et al., 1996; Jett et al., 1991; Zobel and Talbert, 1984). These authors also reported considerable genetic variation in wood density among seed sources. Narrow-sense individual-tree heritability estimates for $P$. taeda have ranged from 0.42 to 1.0 , except for some weak estimates based on juvenile wood (Gwaze, 1997; Gwaze et al., 2001). Isik and Li (2003) also reported high individual-tree (0.61) and family mean heritabilities (0.81 to 0.95 ) for wood density from an 11 year-old diallel test of P. taeda.

Genotype by environment interactions for wood density in the Southeast United States are generally low (i.e., Atwood et al., 2002; Belonger 1996; Byram and Lowe, 1988; Jett et al., 1991). For example, Atwood et al. (2002) reported consistent ranking of Florida source $P$. taeda families for wood density among sites in the Southeast USA. Isik and Li (2003) also reported low general combining ability by site interactions and no specific combining ability by site interaction variances from a diallel test of $P$. taeda. Negligible genotype by environment interaction for wood density was also reported for $\mathrm{Pi}$ - nus elliottii Englem in the southern USA (Hodge and Purnell, 1993). High heritability estimates and insignificant genotype by environment interactions for wood density make the trait amenable for including in $P$. taeda improvement programs.

Most of the previous studies on genetics of wood quality in P. taeda have been based on experimental populations in replicated field tests and with known relationships among the genotypes used. Statistical analysis of this kind of balanced and replicated genetic experiments is relatively straightforward. However, if parents from an operational breeding population are to be sampled, it is likely that progeny tests would be in numerous different sites and at different ages. Parents would have a relatively low representation at any one site. Thus, ranking of sub-sampled parents from different sites and with different ages could be challenging. In this study, we explored a statistical analysis method suggested for unbalanced microarray experiments (Kerr and Churchill, 2001; Kerr et al., 2000; Wolfinger et al., 2001) to predict breeding values of $P$. taeda elite parents sampled from different experiments.

The objectives of this study were (i) to explore a statistical analysis method to predict wood density of elite parents across sites and ages by using a common checklot, (ii) to examine wood density among elite parent trees in seven testing regions in the southeastern USA, and (iii) to estimate genetic variances and heritabilities for wood density within elite populations with trees already selected for rapid growth, straight stems, and fusiform rust resistance.

\section{MATERIALS AND METHODS}

\subsection{Background}

Breeding of $P$. taeda in the North Carolina State UniversityIndustry Cooperative Tree Improvement Program for the second cycle was carried out in three broad breeding zones; the Northern, Atlantic Coastal, and Piedmont zones. The Northern zone had two testing regions (Northern 1 and 2). The Atlantic Coastal zone was subdivided into three testing regions (Coastal 3, 4, and 5), while the Piedmont zone had two regions (Piedmont 6 and 7) (Tab. Ia). Parents of each testing region were grouped into 6-parent diallels for breeding. Parents were mated to produce 15 full-sib families using a disconnected half-diallel mating design (Xiang et al., 2003). In total 574 diallels were planted in the seven regions (Tab. Ia). A diagram of the breeding, testing and selection of the elite parents is given in Appendix 1.

Progeny of two diallels (30 full-sib families) were tested together at four sites within each region. For example, 30 full-sib families from two diallels of Region 4 were only tested in that region. A randomized complete block design with six blocks was used at each test site. Each full-sib family was planted in 6-tree row plots in each block.

In addition to 30 full-sib families, a seed orchard mix checklot was planted at every site within a region. Each region had a separate checklot to measure genetic improvement over the previous (first) breeding cycle. For example, for Region 4, seed orchard mix checklot (SOM4) was planted at all sites within the region but it was not planted across regions (Tab. Ia). The number of seed orchards from which seed were collected to create the mixed checklot ranged from two to five (Tab. Ia). Each orchard contributed approximately $20 \mathrm{fe}-$ male parents to the checklot mix in each region. Thus, depending on 
Table I. Sampling size (parents, crosses, sites sampled) and descriptive statistics of wood density for seven testing regions.

(a) Sampling of seven testing regions in the southeastern USA for assessment of wood density of elite $P$. taeda parents and composition of the reference sample (SOM) in each region.

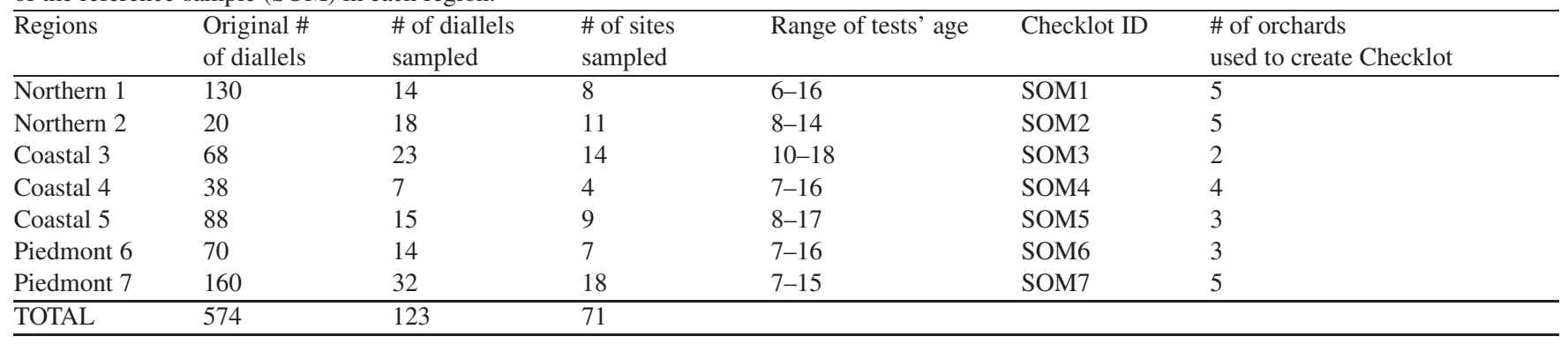

(b) Number of elite parents, crosses and trees sampled from seven testing regions and the descriptive statistics (mean, standard deviation, minimum and maximum) of wood density $\left(\mathrm{kg} / \mathrm{m}^{3}\right)$.

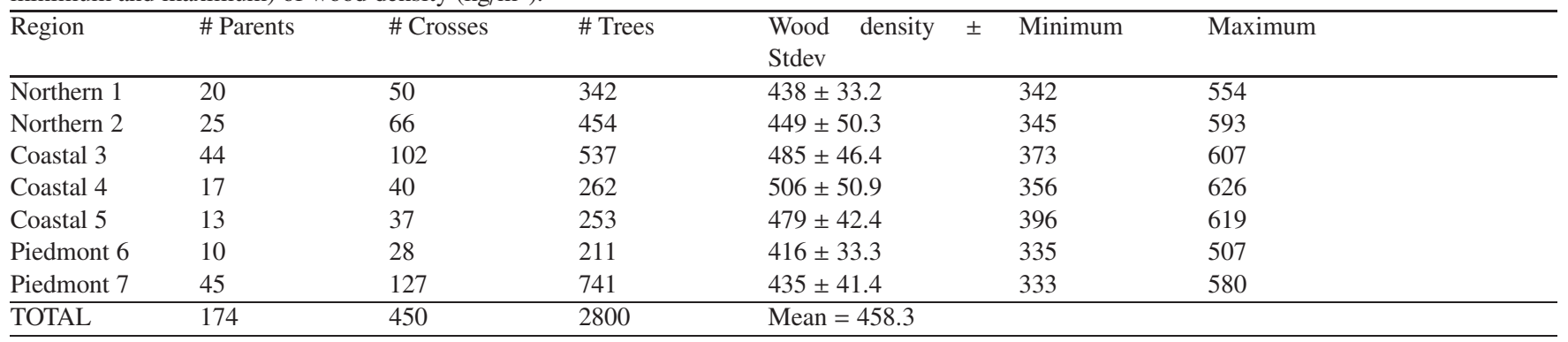

the region, a seed orchard mix of a testing region had a range of 40 to 100 female parents. Unlike full-sib families, the checklot was planted in two row plots in a block. Thus, the checklot was represented by 72 trees at a site to obtain a more reliable mean to compare parents across different diallel tests within a region (Tab. Ia).

After six growing seasons, height, diameter, presence of fusiform rust disease, and stem straightness of trees were measured. Breeding values of parents and their crosses (full-sib families) were predicted using a linear mixed model (Xiang and Li, 2001). The breeding values of parents were later added to the Cooperative data base.

\subsection{Selection of elite parents from the database}

Truncation selection was used to select elite parents within each testing region to study the extent of variation in wood density. The criteria for selection of elite parents were high breeding values for height and bole straightness and low breeding values for fusiform rust infection compared to an unimproved checklot (Fig. 1). In the truncation selection, we chose only parents that had at least $11 \%$ faster growth, $10 \%$ less rust disease infection and $9 \%$ better bole straightness than the unimproved checklot in each region. On average, elite parents had $31 \%$ to $43 \%$ greater volume, $21 \%$ to $25 \%$ greater straightness and $25 \%$ to $51 \%$ less rust infection compared to the unimproved checklot (Fig. 1).

\subsection{Wood sampling from progeny tests}

For each elite parent selected from the database, the three fastest growing full-sib families were chosen for wood sampling. The test site with the highest survival and the lowest plot-to-plot variance was picked among the four sites of a diallel group. For an elite parent, 15 trees ( 3 full-sib families $\times 5$ progeny), all coming from the same

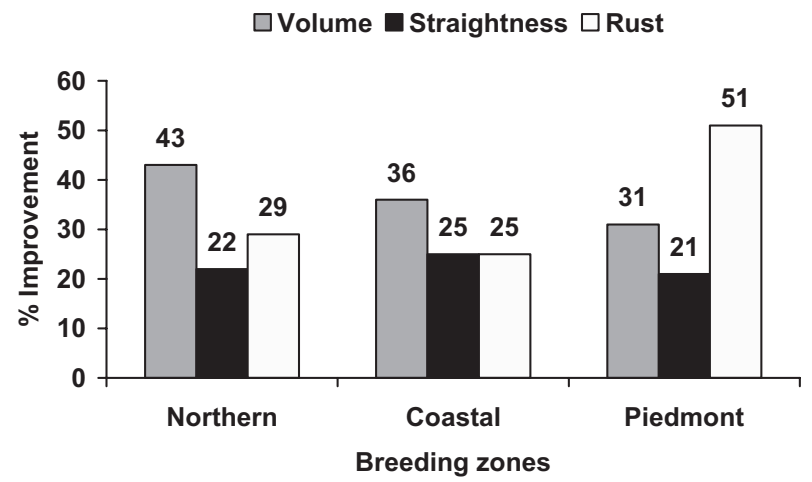

Figure 1. The difference $(\%)$ between average breeding values of elite parents over the unimproved checklots in three geographic breeding zones of P. taeda. A truncated selection was used to select elite parents based on their progeny performance.

site and the same block were sampled. From each sampling site where wood cores were collected, 10 trees of the seed orchard mix were also sampled. At the time of the field sampling, the age of trees in the progeny field trials ranged from 6 to 18 years. The geographic distribution of sampled sites for the seven testing regions is shown in Figure 2. The sampling procedure is also given as a diagram in Appendix 1.

In total, 2800 trees from seven breeding/testing regions were sampled (Tab. Ib). Using gasoline powered drills, 12-mm increment cores were collected at breast height $(1.4 \mathrm{~m})$ in 2003. Increment cores were kept in coolers with ice during collection and were later put into a freezer for long-term storage. The bark was removed from the cores and each core was divided into two pieces at the pith. The last growth ring of all samples was excluded due to missing latewood 


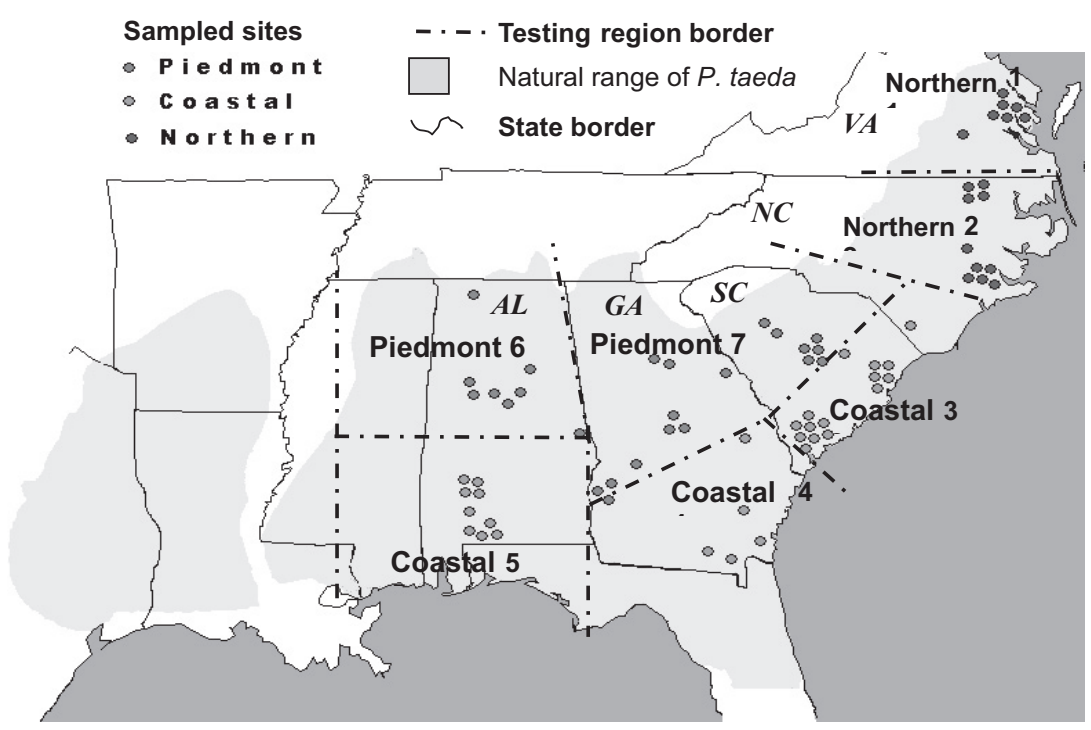

Figure 2. Seven testing regions in three geographic zones (Coastal, Piedmont and Northern) of $P$. taeda improvement program in the Southeast USA. The shaded area is the natural range of the species; the dots represent test sites where elite parents were sampled for wood density in this study.

on cores collected in mid-summer. Half of each core was dried at room temperature for $48 \mathrm{~h}$, and then in an oven at $50{ }^{\circ} \mathrm{C}$ for $24 \mathrm{~h}$, sorted and put into plastic containers. The remaining half cores were stored in a freezer for study of other wood properties. Cores were sectioned longitudinally to produce $2-\mathrm{mm}$ thick strips, which were then conditioned to a uniform moisture content of $8 \%$. Each strip was scanned with an X-ray densitometer from pith to the bark (QMS Tree Ring Analyzer ${ }^{\circledR}$, Model Qtrs-01x, Quintek Measurement Systems Inc., Knoxville, TN). Using the ring area as a weighting factor, weighted core density (called 'wood density' hereafter) values were determined $\left(\mathrm{kg} / \mathrm{m}^{3}\right)$.

\subsection{Statistical analysis}

All the statistical analyses were carried out separately for each region. As the elite parents were mated in a disconnected half-diallel mating design, the pedigree relationships in the data were complex. Most elite parents did not share the same trial (site). In addition, the trees sampled from different trials had different ages, and it is known that wood density increases substantially as the age of $P$. taeda trees increases (Zobel and van Buijtenen, 1989). Since site and age effects were confounded, the data we obtained may violate two assumptions of linear models: Random mating and random sampling of environmental variation (Lynch and Walsh, 1998). Therefore, we used two interconnected linear models to account for environmental variation and to predict breeding values of elite parents. First, a linear regression model was fitted to data to adjust for site and age effects, following a similar approach suggested for microarray experiments (Wolfinger et al., 2001). Gene expression data are complicated by stochastic errors from a variety of sources and need to be adjusted before a genetic model is fit (Cui et al. 2003, Kerr and Churchill, 2001; Wolfinger et al., 2001). We used a seed orchard checklot as a reference sample to remove the confounded site and age effects in the data for each region.

$$
\mathbf{y}=\boldsymbol{\mu}_{1}+\mathbf{X} \boldsymbol{\beta}+\mathbf{e}_{1}
$$

Where, $\mathbf{y}$ is the vector of individual tree wood density values, $\boldsymbol{\mu}_{\mathbf{1}}$ is the common intercept, $\boldsymbol{\beta}$ is the vector of fixed checklot (one checklot mean for each trial), $\mathbf{X}$ is the design matrix relating the $\boldsymbol{\beta}$ to $\mathbf{y}$, and $\mathbf{e}_{1}$ is the stochastic error matrix. It was assumed that the expected value of errors is $\mathrm{E}\left(\mathbf{e}_{\mathbf{1}}\right)=0$. The errors have a constant variance and are uncorrelated, thus the $\mathbf{R}=\mathbf{I} \sigma_{\mathrm{el}}^{2}$ is a diagonal matrix with the error variances $\left(\sigma_{\mathrm{e}}^{2}\right)$ in the diagonal and 0 values in the off diagonals (Littell et al., 1996). The $\mathbf{X} \boldsymbol{\beta}$ matrix in Equation (1) fits a linear regression and shrunk the density values towards the checklot mean in the trial. The model was run using the SAS MIXED procedure (SAS Institute, 1996). The predicted values from the model are formed as $\mathbf{X} \hat{\boldsymbol{\beta}}$. The residuals (r) are the difference between observed $(\mathbf{y})$ and predicted values $\mathbf{X} \hat{\boldsymbol{\beta}}$. They are age and site adjusted (normalized) wood density values.

$$
\mathbf{r}=\mathbf{y}-\mathbf{X} \hat{\boldsymbol{\beta}}
$$

The OUTP = option in the MIXED procedure of SAS was used to obtain residuals. The following linear mixed model was fit to the residuals (normalized wood density values) to predict breeding values and estimate variance components.

$$
\mathbf{r}=\boldsymbol{\mu}_{2}+\mathbf{Z u}+\mathbf{e}_{2}
$$

Where $\mathbf{r}$ denotes the column vector of residuals, $\boldsymbol{\mu}_{2}$ is the intercept, $\mathbf{u}$ is a matrix of random effects, that includes parent effects (GCA), and cross effects (SCA), and $\mathbf{Z}$ is a design matrix for random effects. The model (3) does not include parent by site or full-sib family by site interactions due to data structure. The covariance matrix of observations is $\operatorname{Var}(\mathbf{y})=\mathbf{Z G} \mathbf{Z}^{T}+\mathbf{R}$ (Littell et al., 1996). The first term (G) accounts for genetic effects, while the second term $(\mathbf{R})$ accounts for random residual effects. The expectations of random factors are 0 mean with variances $\sigma_{\mathrm{gca},}^{2} \sigma_{\mathrm{sca}}^{2}$, and $\mathbf{I} \sigma_{\mathrm{e} 2}^{2}$.

The elements of $\mathbf{G}$ are the products of additive genetic relationship matrix $\mathbf{A}$ and the variance of additive genetic effects $\sigma_{\mathrm{A}}^{2}\left(\mathbf{G}=\mathbf{A} \sigma_{\mathrm{A}}^{2}\right)$. 
The elements of relationship matrix $\mathbf{A}$ are genetic covariances between relatives and are given by $2 \Theta_{\mathrm{ij}} \sigma_{\mathrm{e}}^{2}$, where $\Theta_{\mathrm{ij}}$ is the coefficient of coancestry. The inverse A matrix was created using a pedigree file and implemented by the ASReml software (Gilmour et al., 2002). ASReml is a likelihood-based program for variance components and was developed to handle complex pedigree relationships among the genotypes. Best linear unbiased estimators (BLUE) of fixed effects, best linear unbiased predictors (BLUP) of parents (GCA values) and full-sib families (SCA) were estimated from normalized wood density by solving the mixed model Equation (3) using ASReml. Using variance components from the genetics effects model, individual-tree narrow-sense heritabilities $\left(h_{\mathrm{i}}^{2}\right)$ and half-sib family means heritabilities $\left(h_{\mathrm{hs}}^{2}\right)$ were estimated according to the following formulas.

$$
\begin{gathered}
h_{\mathrm{i}}^{2}=\frac{4 \sigma_{\mathrm{gca}}^{2}}{2 \sigma_{\mathrm{gca}}^{2}+\sigma_{\mathrm{sca}}^{2}+\sigma_{\mathrm{e}}^{2}} \\
h_{\mathrm{hs}}^{2}=\frac{\sigma_{\mathrm{gca}}^{2}}{\frac{1}{p-1}\left(p \sigma_{\mathrm{gca}}^{2}+\sigma_{\mathrm{sca}}^{2}+\frac{\sigma_{\mathrm{e}}^{2}}{n}\right)}
\end{gathered}
$$

where, $\sigma_{\mathrm{gca}}^{2}$ and $\sigma_{\mathrm{sca}}^{2}$ are variance components for normalized wood density explained by the additive, and non-additive genetic effects, respectively, $\sigma_{e}^{2}$ is the error variance, $n$ is the average family size, $p$ is the number of parents. Standard errors of heritabilities were estimated using the Delta method (Lynch and Walsh, 1998) and implemented with a SAS/IML code.

Stability of seed orchard mix checklots across trials was evaluated by regressing the checklot means (the mean of checklot trees) on trial means (the mean of all progeny of parents). The joint regression method suggested by Finlay and Wilkinson (Finlay and Wilkinson, 1963) characterizes interaction by a series of regression coefficients, which are taken as stability of the genotypes (McKeand et al., 1990). The regression coefficient $\beta_{1}$ for each region was tested as $H_{0}: \beta_{1}=1.0$ using the TEST statement of the REG procedure of SAS (1996). The REG procedure performs an $F$ test for the hypotheses specified in the TEST statement. If the regression coefficient is $b=1.0$ and residual mean squares is small, then the checklot was considered to have an average stability. An average stable checklot would be preferred for data normalization because such response would be highly correlated with the average performance of parents. Regression coefficients that deviates significantly from 1.0 suggest that either the checklot is unstable $(b>1.0)$ or not responsive $(b<1.0)$ to changing environment (McKeand et al., 1990).

\section{RESULTS}

\subsection{Comparison of testing regions}

Wood density for individual trees ranged from 333 to $626 \mathrm{~kg} / \mathrm{m}^{3}$, whereas the average wood density for seven testing regions varied from 416 to $506 \mathrm{~kg} / \mathrm{m}^{3}$ (Tab. Ib). The descriptive statistics of wood density for testing regions are based on measurements before removing age and site effects (before normalization). The Coastal testing regions had greater wood density than the two Piedmont and two Northern testing regions (Tab. Ib). The three Coastal regions had average wood density of 485 (Coastal 3), 506 (Coastal 4) and 479 (Coastal 5) $\left(\mathrm{kg} / \mathrm{m}^{3}\right)$. These estimates were consistently greater than the average of Piedmont 6 (416) and Piedmont 7 (435) regions. The
Table II. Regression results of checklots' wood density means (seed orchard mixes) on site means (average of all sampled parents) for different testing regions.

\begin{tabular}{lccccc}
\hline Region & $R^{2}$ & $\beta_{1}$ & $\beta_{1}, P r>\mathrm{F}^{1}$ & Residual MS & Number of trials \\
\hline Northern 1 & 0.89 & 1.00 & 0.997 & 7.9 & 8 \\
Northern 2 & 0.96 & 1.02 & 0.771 & 9.2 & 11 \\
Coastal 3 & 0.77 & 0.61 & 0.003 & 11.7 & 13 \\
Coastal 4 & 0.79 & 0.78 & 0.526 & 20.0 & 4 \\
Coastal 5 & 0.16 & 0.20 & 0.002 & 17.0 & 9 \\
Piedmont 6 & 0.94 & 1.12 & 0.384 & 6.1 & 7 \\
Piedmont 7 & 0.91 & 1.01 & 0.859 & 11.0 & 18 \\
\hline
\end{tabular}

${ }^{1}$ Regression coefficients $\left(\beta_{1}\right)$ with a probability value $(\operatorname{Pr}>F)$ greater than 0.05 are not significantly different from 1.0, indicating a stable reference sample (checklot) across sites.

two Northern regions had slightly greater average wood density $\left(438\right.$ and $449 \mathrm{~kg} / \mathrm{m}^{3}$ ) than the Piedmont testing regions.

\subsection{Stability of checklots}

Checklots had average stability across sites within a testing region, except for Coastal regions 3 and 5 (Tab. II). As the trial wood density increased, the checklot mean increased accordingly as shown by the regression coefficients $\left(\beta_{1}\right)$. The linear regression slopes $\left(\beta_{1}\right)$ were not significantly different from 1.0 for five regions out of seven. Regressing the checklot means on trial means accounted for $77 \%$ to $95 \%$ of the variance in wood density, except for the region Coastal 5. The relationship between family means and the checklot SOM5 in the Coastal 5 region was exceptionally weak. This region had also one of the highest residual means squares, suggesting lack of fit. Regression coefficients smaller than 1.0 for regions 3 and 5 suggest that the checklots in these two regions are stable, that is they did not response to average site density values. In other words, when the average site wood density increased, the checklots SOM3 and SOM5 did not increase correspondingly.

\subsection{Adjustment for age effects}

The relationships between the age of the trial and average wood density of the trial before and after data normalization were examined for all regions. For demonstration purposes and for simplicity, plots of trial age ( $x$-axis) and trial wood density mean ( $y$-axis) for the Piedmont 6 and Piedmont 7 regions only are shown (Fig. 3). The Piedmont 7 region is a good representative of a region with a relatively large number of trials (18), with a good spread of test ages, whereas the Piedmont 6 region is a representative of a region with a smaller number of trials (7) with uneven distribution of means (Fig. 3). The relationship between the trial age and the average wood density of the trial was linear and strong in Piedmont 7 test region (Fig. 3a), indicating that as the trial age increased average wood density increased accordingly $\left(R^{2}=0.68\right)$. The normalization model was successful in removing the age effects on 
(a)
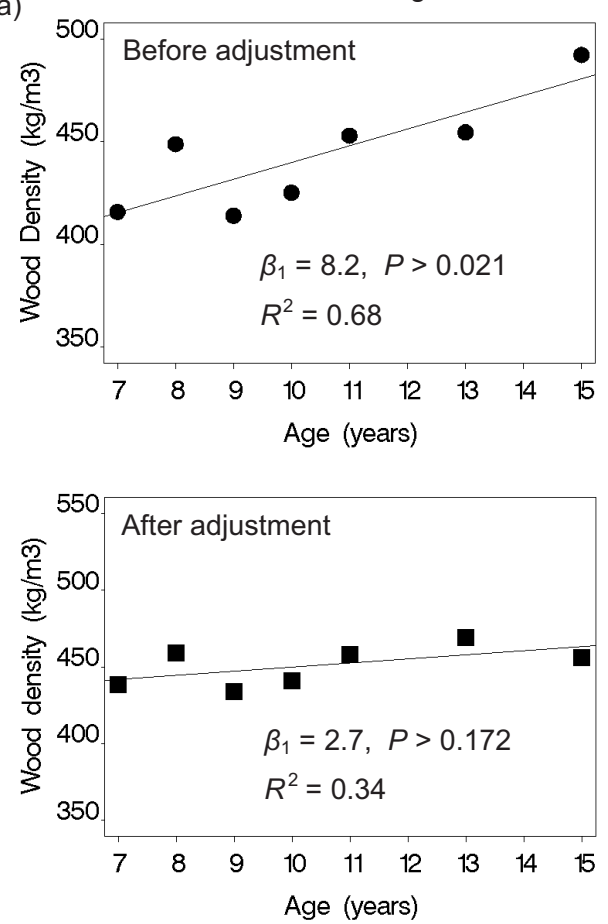

(b)
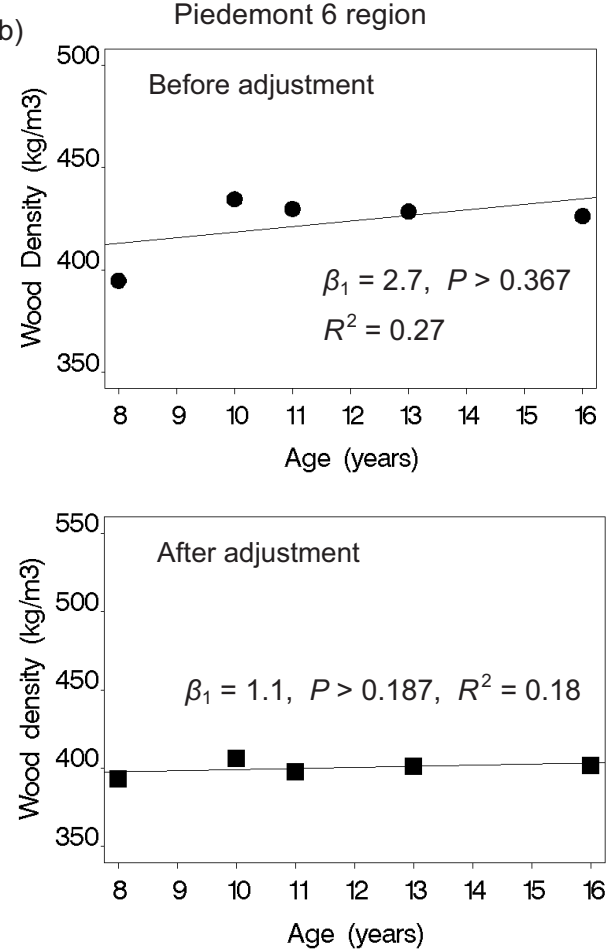

Figure 3. Age effects on average wood density values for two testing regions before and after data normalization using the checklot means. $\beta_{1}$ is the regression coefficient (slope), $\mathrm{R}^{2}$ is the coefficient of determination, $\operatorname{Pr}$ is the $\mathrm{F}$ statistic probability value of the slope. Some sites had the same ages and thus, the number of data points visible is less than the actual number of sites. (a) Age effects on average wood density in Piedmont 7 testing region. The age of 18 trials ranged from 7 to 15 years. Because some of the trials were at the same ages, the actual number of point in the regression models is smaller than 18. (b) Age effects on average wood density values in Piedmont 6 testing region. The age of seven trials ranged from 7 to 16 years. Because some of the trials were at the same ages, the actual number of point in the regression models is smaller than seven.

wood density values in Piedmont 7 region $\left(R^{2}=0.34\right)$. For example, after the data normalization, the relationship (regression slope) between the trial age and normalized wood density was not significantly different from zero in the Piedmont 7 region $(P<F=0.172)$. In the Piedmont 6 region (Fig. 3b), the age-site density relationship before normalization was linear positive but weak $\left(R^{2}=0.27\right)$. With the data normalization, the coefficient of determination was considerably reduced $\left(R^{2}=0.18\right)$. The normalization model was also successful in removing age effects on density for all other breeding regions (data not presented), except Region 5.

For all the regions, the distribution of empirical quantiles from the linear regression model and the quantiles of a standard normal distribution were examined. As representative of a large and a small sample size, the plots of the Piedmont 6 and Piedmont 7 regions are presented in Figure 4. The normalized wood density values (residuals) tend to fall along the reference line indicating an approximately normal distribution (Fig. 4a). We did not observe a trend in the distribution of residuals from mixed models (Eq. (3)) for the Piedmont 6 and Piedmont 7 regions (Fig. 4b). The distribution of normalized wood density values in Piedmont 6 region was discontinuous due to small number of trials in this region.

\subsection{Variance components and heritability estimates}

We detected considerable genetic variation in wood density among the fast growing elite parents in all seven testing regions, except for the Piedmont 6 region (Tab. III). General combining ability variance in the testing regions ranged from 0 (Piedmont 6) to 39\% (Coastal 5) of the total phenotypic variance, whereas the specific combining ability variance accounted for 0 (Coastal 3 and 5) to $22 \%$ (Piedmont 6). When Piedmont 6 region is excluded, general combining ability variance was considerably lower in two Northern regions compared to the rest of regions. As expected, error variance in each testing region was large and accounted for 59 (Coastal 4) to $88 \%$ (Northern 2) of the total variance. Most of the variances were associated with high approximate standard errors.

High genetic variation among parents in six testing regions was reflected in moderate to high heritabilities. Individualtree heritability in the Northern 1 region was considerably smaller (0.12) than the estimates in other regions. Individualtree narrow-sense heritability in the other five regions ranged from 0.31 to 1.00 . Heritability was not estimable in the Piedmont 6 region due to lack of additive genetic variance. In all six regions, individual-tree heritabilities were associated with high standard errors. Heritabilities of half-sib family means for 
(a)
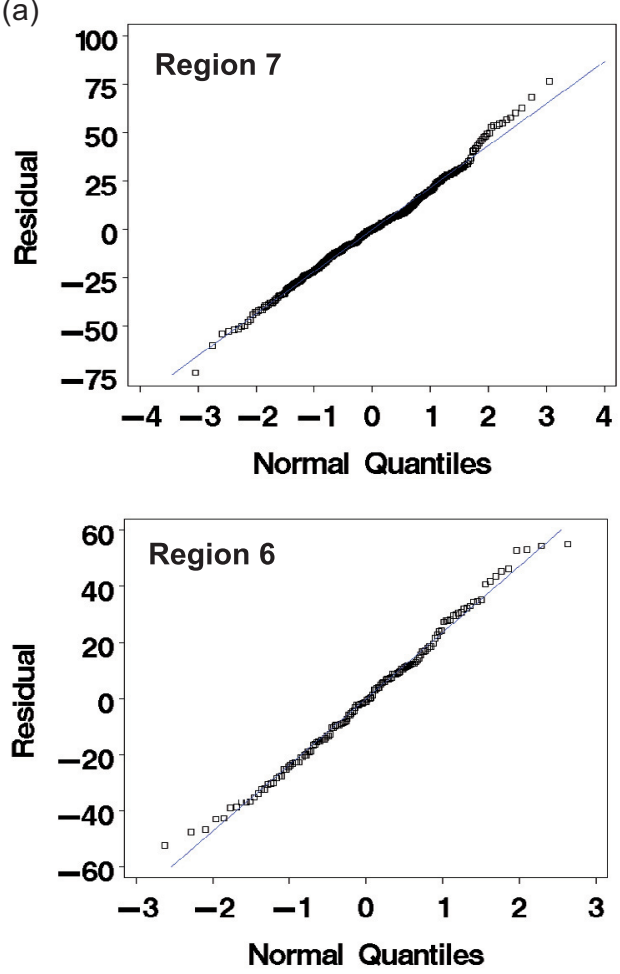

(b)
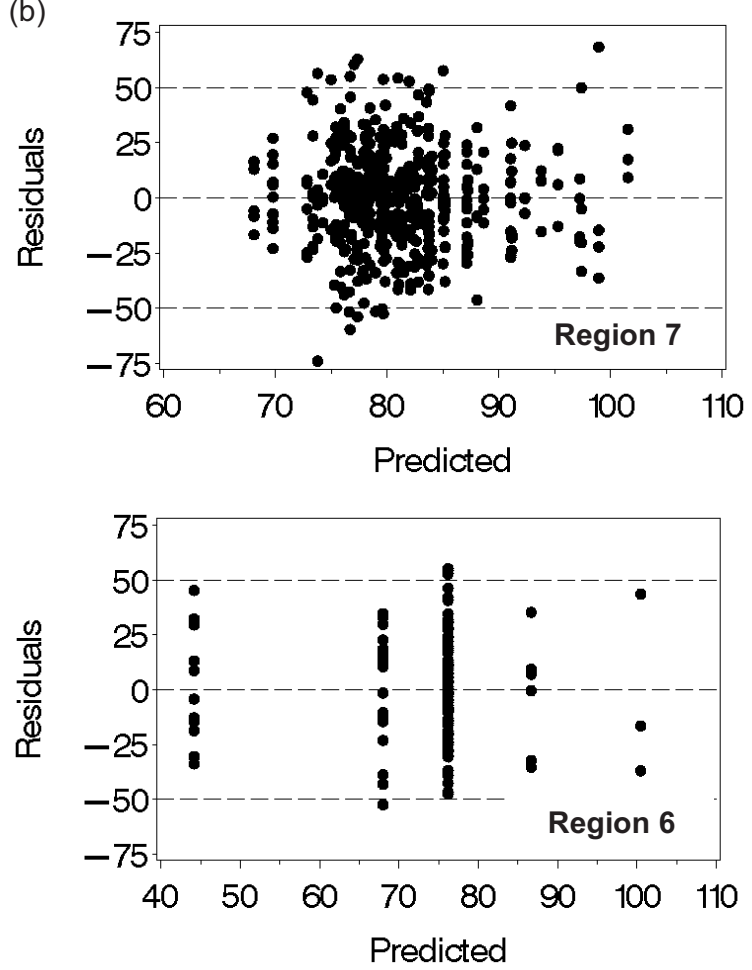

Figure 4. Examination of normalized wood density values of Piedmont 6 and Piedmont 7 testing regions of $P$. taeda. (a) Normal probability plots of normalized wood density values (empirical residuals) of two regions after fitting linear regression models. (b) Residuals versus predicted wood density values of Piedmont 7 and Piedmont 6 regions after fitting linear mixed models (Eq. (3)). The lack of an apparent trend in the distribution of residuals suggests that the assumption of constant error variance was not violated.

Table III. Variance components, approximate standard error of variance components $( \pm \mathrm{SE})$, percent of total phenotypic variance explained by each factor (\%), individual-tree narrow sense $\left(h_{\mathrm{i}}^{2}\right)$ and half-sib family mean $\left(h_{\mathrm{hs}}^{2}\right)$ heritabilities of wood density in seven testing regions of Pinus taeda in the southeastern US.

\begin{tabular}{lccccccc}
\hline Regions & $\sigma_{\mathrm{GCA}}^{2} \pm \mathrm{SE}$ & $\%$ & $\sigma_{\mathrm{SCA}}^{2} \pm \mathrm{SE}$ & $\%$ & $\sigma_{\mathrm{E}}^{2} \pm \mathrm{SE}$ & $h_{\mathrm{i}}^{2} \pm \mathrm{SE}$ & $h_{\mathrm{hs}}^{2} \pm \mathrm{SE}$ \\
\hline Northern 1 & $20 \pm 37$ & 3 & $114 \pm 78$ & 18 & $498 \pm 49$ & $0.12 \pm 0.22$ & $0.79 \pm 0.07$ \\
Northern 2 & $75 \pm 52$ & 9 & $29 \pm 81$ & 3 & $781 \pm 68$ & $0.31 \pm 0.20$ & $0.88 \pm 0.06$ \\
Coastal 3 & $236 \pm 137$ & 21 & 0 & 0 & $884 \pm 70$ & $0.70 \pm 0.27$ & $0.97 \pm 0.02$ \\
Coastal 4 & $468 \pm 202$ & 28 & $207 \pm 128$ & 13 & $979 \pm 116$ & $0.88 \pm 0.23$ & $0.91 \pm 0.04$ \\
Coastal 5 & $377 \pm 365$ & 39 & 0 & 0 & $587 \pm 71$ & $1.00 \pm 0.49$ & $0.90 \pm 0.09$ \\
Piedmont 6 & 0 & 0 & $181 \pm 85$ & 22 & $630 \pm 82$ & not estimable & not estimable \\
Piedmont 7 & $135 \pm 44$ & 17 & $131 \pm 59$ & 16 & $553 \pm 38$ & $0.57 \pm 0.15$ & $0.71 \pm 0.09$ \\
\hline
\end{tabular}

${ }^{1} \sigma_{\mathrm{GCA}}^{2}$ is the general combining ability variance, $\sigma_{\mathrm{SCA}}^{2}$ is the specific combining ability variance, $\sigma_{\mathrm{E}}^{2}$ is the error variance, SE is the standard error.

wood density were high in all six regions that were estimable, ranging between 0.71 (Piedmont 7 ) and 0.97 (Coastal 3), with relatively smaller standard errors compared to individual-tree narrow-sense heritabilities.

\section{DISCUSSION}

Elite parents selected for superior growth, fusiform rust disease resistance and bole straightness had considerable variation for wood density. Wood density was higher in the Coastal
P. taeda testing regions (coastal Georgia and South Carolina) compared to the more inland (Piedmont) and northern (North Carolina and Virginia) regions. The difference among the testing regions for wood density is contributed partly by the environment, such as temperature, the length of the growth period and precipitation, and partly by genetic differences between families tested in each region (Jett et al., 1991). Because families were tested separately within regions, not across regions, the environmental and genetic effects are not separable. However, the trends observed in density of different regions are consistent with the previous reports on environmental and 
genetic effects. Environmental variables may have considerable effect on wood density. The same genotypes may produce denser wood in one environment than in another if there are considerable temperature and precipitation differences between them (Jayawickrama et al., 1997; Jett et al., 1991). Using 18 half-sib families and four provenances, Jett et al. (1991) reported significant environmental effects on wood density of $P$. taeda provenances and families. In the same study, average wood density $\left(\mathrm{kg} / \mathrm{m}^{3}\right)$ of the same seed sources in different sites ranged from 406 (in Virginia) to 461 (in Georgia) and site effects accounted for $32 \%$ of the total variation in wood density. Significant effect of environment on wood density was also reported by Byram and Lowe (1988) and Zobel and van Buijtenen (1989). The higher wood density produced in the coastal regions compared to the inland regions is explained by longer growth period in the coastal plains, where trees take the advantage of available soil moisture and milder temperatures to add more latewood in the later growth period (Zobel and van Buijtenen, 1989). In a more recent study, Gwaze et al. (2001) studied wood density of 33 open-pollinated $P$. taeda families selected from western Mississippi. They found that, wood density of the same families was higher in a slower growing site than the wood density in a faster growing site. Cumbie (2002) also reported lower wood density for a rapid growth site $\left(425 \mathrm{~kg} / \mathrm{m}^{3}\right)$ in Alabama than a slower growing site $\left(444 \mathrm{~kg} / \mathrm{m}^{3}\right)$ in Florida in a factorial cloned genetic test of P. taeda.

Genetic differences among provenances or populations are another important source of variation in wood density. When grown together, more southerly provenances tend to have lower wood density than seed sources from the Piedmont and Northern seed sources. Jett et al. (1991) found significant differences among 18 families tested over seven widely separated sites in the Southeast USA. In the same study, three southern $P$. taeda provenances had consistently lower wood density than northern and Piedmont seed sources. Similar results were also reported by Byram and Lowe (1988), and Tauer and LooDinkins (1990). The lower wood density of southern provenances has been attributed to shoot elongation patterns, slower formation of the latewood (Jett et al., 1991), and time of transition from springwood to summerwood production (Byram and Lowe, 1988).

This study focused on documenting wood density of progeny from elite parents of an entire breeding population in different regions as opposed to others that studied relatively few families tested across fewer numbers of balanced trials. The findings from this study are based on wood cores sampled from 71 experimental test sites that cover an area spanning most of the natural distribution range of the species. However, the patterns of geographic variation in wood density in this study are largely similar to those found in the previous studies. Average wood density in the Atlantic coastal plains was higher than the average wood density in inland (Piedmont) and northern (North Carolina and Virginia) regions. Since the environment and genetics trends geographically are opposite, much of among-region variation in wood density can be attributed to environment rather then genetics.

\subsection{Stability of checklots and removal of confounded age and site effects}

Estimating breeding values of elite parent trees in breeding populations of forest trees can be challenging, when elite parents come from different breeding units, such as disconnected diallels. For logistical reasons, it is common to test breeding units in different years and at different sites. This introduces age differences among trials and, thus, among parents. When comparing elite parents for a secondary trait such as wood density, the confounded age and site effects need to be accounted for. In this study, we used seed orchard mixes to adjust for confounding site and age effects within testing regions.

The response of a reference sample (checklot) to different environments can be critical for evaluating the performance of elite parents across trials. For normalization of data, an average stable checklot is preferred, as suggested by McKeand et al. (1990). In general, the reference samples (seed orchard mixes) in this study were stable across most sites and they could be used to compare parents across sites. The exception was Coastal 5 region. The exceptionally weak relationship $\left(R^{2}=0.16\right)$ between the checklot means and trial means in Coastal 5 region may have originated from a relatively high trial mean and a low checklot mean in one trial in southern Alabama (data not shown). The reason for such a low checklot mean is not known but could be sampling error. The sample size of the checklot could be another underlying factor for such a weak relationship. When the reference sample is not stable across sites, then the empirical wood density breeding values of elite parents might be underestimated or over estimated depending on the response of the checklot to sites. For the Coastal 5 region, wood density of elite parents may be overestimated due to greater deviation of family wood density means from the checklot mean on a specific site. In such a case, a conservative selection approach could be preferred, such as limiting selection to within each diallel series rather than ranking parents across diallels for selection.

The normalization method used in this study appeared to be a viable method to account for variability across sites and remove confounding age effects in a testing region, except in Region 5. Regressing the checklot means on site means could be employed to test the stability of the checklots, but that method may require a large number of sites (i.e., > 15) (Finlay and Wilkinson, 1963). Checklot means based on small number of trees (i.e., < 10) may not be reliable. The data normalization method used in this study may not be efficient if genotypes by environment interactions are significant. Several normalization methods have been suggested for microarray gene expression data to remove extraneous effects (Cui et al., 2003; Kerr and Churchill, 2001; Kerr et al., 2000). Two interconnected linear mixed models have been suggested to account for variability both across and within microarray slides (Jin et al., 2001). The reference sample design has been recommended to connect all samples of microarray experiments due to the logistic difficulty of testing of large numbers of genotypes (Kerr et al., 2000; Wolfinger et al., 2001). The disadvantage of the reference design is that a great deal of resources is allocated for testing the reference sample. This is also the 
case in forest progeny testing programs. Logistical limitations and the time required for breeding of most forest trees requires using checklots for comparisons of parents in a breeding program.

An alternative approach to remove extraneous age, but not site, effects could have been to exclude all the portions of wood cores not present in all sampled trees, e.g., keeping the wood up to the youngest age among trials. However, because some trials were as young as age six, and these were a small proportion of all trials, this approach would have resulted in discarding much useful data.

The application of two interconnected linear models used in this study met the major assumptions of analysis of variance. The site and age adjusted wood density values were approximately normal (Fig. 4a). The lack of an obvious trend in the plots of residuals versus predicted values (Fig. 4b) from the mixed model suggested that the error variance was constant across sites. Log transformation is another commonly used method in analysis of gene expression data to obtain residuals with a constant variance (Huber et al., 2002; Kerr and Churchill, 2001). Transformation has its own drawbacks, e.g., the difficulty in interpreting breeding values. The two linear models used in this study did not require data transformation to meet the normal and independent distribution of residuals assumption of analysis of variance.

\subsection{Variance components and heritability}

Elite parents selected for superior growth, straighter stems and resistance to fusiform rust disease were highly variable for wood density in all seven testing regions. Additive genetic effects explained up to $39 \%$ of the total variance for wood density, whereas non-additive genetic effects explained up to $22 \%$. Cumbie (2002) also reported up to $30 \%$ of additive genetic variance, but near zero non-additive genetic variance for wood density from a cloned factorial mating experiment of $P$. taeda. However, the magnitude of additive and dominance genetic variances in seven testing regions was not consistent. Additive genetic variance was zero in the Piedmont 6 region, but dominance genetic effects explained $22 \%$ of the total phenotypic variance. Similarly, additive genetic effects explained only $3 \%$ of the total variation in the Northern 1 testing region, whereas dominance genetic variance was much higher $(18 \%)$. Narrow-sense individual-tree heritability for wood density was only 0.12 in the Northern 1 region, whereas it was 1.00 in the Coastal 5 region. The discrepancy among regions might be explained by the relatively small numbers of parents sampled within each region, or by actual genetic differences among parents tested in regions. The half-sib family heritability estimates (based on elite parents) of the six estimable testing regions ( 0.71 to 0.97$)$ were within the range of estimates reported in the literature (Zobel and van Buijtenen, 1989). In general, wood density is under strong additive genetic control in P. taeda and narrow-sense heritability is usually at least 0.50 (Megraw, 1985), with the exceptions of some weak estimates for juvenile wood (Gwaze et al., 2001). Half-sib family heritabilities from a cloned P. taeda experiment were 0.71 (based on clones) and 0.68 (based on seedlings) (Cumbie, 2002). The results in this study generally agree with previous studies on genetic control of wood density in P. taeda, despite differences in experimental designs, sampling and statistical analysis methods used. This suggest that the approach of measuring a secondary trait, such as wood density, on previously selected elite parents across an entire breeding populations, with appropriate statistical analysis is a viable one.

The heritability estimates reported in this study may be biased upward due to non-random mating of parents in the population. In this study, parent trees did not share a common pollen pool, but were mated to different sets of other parents. In addition, predicting wood density of the fast growing crosses may have introduced bias due to small sample size in some regions. Moreover, we do not know possible effects of sampling fast growing trees on wood density. Some studies suggested that fast growing families do not necessary produce less dense wood compared to slower growing families in loblolly pine (Megraw, 1985). Possible genotype by environment interactions may have also contributed to biased estimates of heritabilities. However, the genotype by environment interaction effect is probably small in $P$. taeda. Cumbie (2002), Isik and Li (2003), Atwood et al. (2002), and Jett et al. (1991) reported non significant genotype by environment interactions for wood density of $P$. taeda. The error variance in this study is not true 'within-family' variance but a stochastic term that may also have affected the estimates. Nevertheless, heritability estimates were within the expected range of heritabilities estimated for wood density of P. taeda (Isik and Li, 2003; Jett et al. 1991; Zobel and van Buijtenen, 1989). The results for the Coastal 5 testing region should be evaluated with reservations. The linear regression models were less effective in removing confounding age and site effects for the regions with smaller numbers of test sites and families.

\subsection{Implications for improvement of wood density}

These results have implications for improvement of wood density in P. taeda breeding populations in the Southeast USA. Although parents selected for this study had superior growth and stem straightness, we observed considerable genetic variation in wood density among parents. High half-sib family mean heritabilities suggest that considerable genetic gains could be achieved when elite parents are further selected for wood density. Such elite parents with high wood density can be mated in mass controlled pollinations and full-sib family blocks can be established to increase wood density in plantations managed for solid wood products. Forest industry in the Southeast USA has already been practicing family forestry to capture additive and non-additive genetic variance (McKeand et al., 2003). Alternatively, full-sib progeny can be cloned and tested in replicated field trials and clones with high wood density can be mass propagated for deployment. Finally, elite parents or clones with high wood density could be used in a specialized elite breeding population to increase wood density among trees already selected for growth, straightness and disease resistance. The median age of trees sampled for this 
study was about 12 years, which is about half of the rotation age of $P$. taeda plantations. Age-age correlations of wood density need to be explored for fast growing elite families to study possible undue effect on growth traits. In the literature, strong age-age correlations were reported for wood density in hybrid poplar clones (Pliura et al., 2006). Wu et al. (2007) reported stable wood density values from ages $11-15$ to rotation-age in Pinus radiata, which is encouraging.

\section{CONCLUSIONS}

Prediction of breeding values of a sub-sample of parents from an operational tree breeding program can be challenging, as data are greatly complicated by errors from different sources, such as site and age effects. Using checklots (reference samples) to remove site and age effects appears to be an effective method for genetic analysis of a secondary trait, such as wood density. In a sub-sample of the breeding population, the stability of the reference sample can be critical in data normalization and the checklot should be tested for stability before data normalization. We found considerable genetic variation for wood density among elite parents of $P$. taeda in testing regions in the southern USA, suggesting the opportunity to improve this economically important trait among trees already selected for other traits.

Acknowledgements: This study was funded by grants from CSREES-USDA (Contract / Grant / Agreement No.: 2001-5210411224) and the Department of Energy, the North Carolina Agricultural Research Service and the members of the North Carolina State University-Industry Cooperative Tree Improvement Program. We thank members of the NC State University-Industry Cooperative Tree Improvement Program for their generous help in collecting wood samples across the southern USA. We are also grateful to Houmin Chang, Ron Sederoff, and John Kadla for insightful suggestions on the study. We thank three reviewers for excellent suggestions to improve the manuscript.

\section{REFERENCES}

Atwood R.A., White T.L., and Huber D.A., 2002. Genetic parameters and gains for growth and wood properties in Florida source loblolly pine in the southeastern United States. Can. J. For. Res. 32: 1025-1038.

Belonger P.J., 1998. Variation in selected juvenile wood properties in four southern provenances of loblolly pine. M.S. thesis, North Carolina State University, Raleigh, NC, 174 p.

Belonger P.J., McKeand S.E., and Jett J.B., 1996. Genetic and environmental effects on biomass production and wood density in loblolly pine. In: Dieters M.J., Matheson A.C., Nikles D.G., Harwood C.E., Walker S.M. (Eds.), Tree improvement for sustainable tropical forestry QFRI IUFRO Conference, Queensland, Australia, 27 October 1996.

Byram T.D. and Lowe W.J., 1988. Specific gravity variation in a loblolly pine seed source study in the western Gulf region. For. Sci. 34: 798803.

Cown D.J., 1978. Comparison of the Pilodyn and torsiometer methods for the rapid assessment of wood density in living trees. N. Z. J. For. Sci. 8: 384-391.

Cui X., Kerr M.K., and Churchill G.A., 2003. Transformations for cDNA microarray data. Stat. Appl. Genet. Mol. Biol. 2: 1-10.
Cumbie W.P., 2002. Variation of wood density traits in rooted cuttings and seedlings of loblolly pine. MS Thesis. North Carolina State University, Raleigh, NC, 97 p.

Finlay K.W. and Wilkinson G.N., 1963. The analysis of adaptation in a plant-breeding programme. Aust. J. Agric. Resour. Econ. 14: 742754.

Gilmour A.R., Gogel B.J., Cullis B.R., Welham S.J., and Thomson R., 2002. ASREML User Guide, Release 1.0. VSN International Ltd, Hemel Hempstead, HP1, 1ES, UK. 267 p.

Gough G. and Barnes R.D., 1984. A comparison of three methods of wood density assessment in a Pinus elliottii progeny tests. S. Afr. For. J. 128: 22-25.

Gwaze D.P., 1997. Genetic parameter estimates for height and stem straightness in Pinus taeda Linnaeus and implications for breeding. Ph.D. thesis, University of Edinburgh, Edinburgh, Scotland, p. 284.

Gwaze D.P., Bridgwater F.E., Byram T.D., and Lowe W.J., 2001. Genetic parameter estimates for growth and wood density in loblolly pine (Pinus taeda L.). For. Genet. 8: 47-55.

Hodge G.R. and Purnell R.C., 1993. Genetic parameter estimates for wood density, transition age and radial growth in slah pine. Can. J. For. Res. 23: 1881-1891.

Huber W., von Heydebreck A., Sultmann H., Poustka A., and Vingron M., 2002. Variance stabilization applied to microarray data calibration and to the quantification of differential expression. Bioinformatics 18(Suppl. 1): S96-S104.

Isik F. and Li B., 2003. Rapid assessment of wood density of live trees using the Resistograph for selection in tree improvement programs. Can. J. For. Res. 33: 2426-2435.

Jayawickrama K.J.S., McKeand S.E., Jett J.B., and Wheeler E.A., 1997. Date of earlywood-latewood in provenances and families of loblolly pine, and its relationship to growth phenology and juvenile wood specific gravity. Can. J. For. Res. 27: 1245-1253.

Jett J.B., McKeand S.E., and Weir R.J., 1991. Stability of juvenile wood specific gravity of loblolly pine in diverse geographic areas. Can. J. For. Res. 21: 1080-1085.

Jin W., Riley R.M., Wolfinger R.D., White K.P., Gisele P.G., and Gibson G., 2001. The contributions of sex, genotype and age to transcriptional variance in Drosophila melanogaster. Nature Genet. 29: 389395.

Kerr M.K., Martin M., and Churchill G.A., 2000. Analysis of variance for gene expression microarray data. J. Comp. Biol. 7: 819-837.

Kerr M.K. and Churchill G.A., 2001. Statistical design and the analysis of gene expression microarrays (invited review). Genet. Res. 77: 123128.

Li B., McKeand S.E. and Weir R.J., 1999. Tree improvement and sustainable forestry - impact of two cycles of loblolly pine breeding in the US. For. Genet. 6: 229-234.

Littell R.C., Milliken G.A., Stroup W.W., and Wolfinger R.D., 1996. SAS System for Mixed Models. Cary, N.C.: SAS Institute Inc., 633 p.

Lynch M. and Walsh B., 1998. Genetics and Analysis of Quantitative Traits. Sinauer Associates, Inc., Sunderland, MA, 980 p.

McKeand S.E., Li B., Hatcher A.V., and Weir R.J., 1990. Stability of parameter estimates for stem volume for loblolly pine families growing in different regions in the southeastern United States. For. Sci. 36:1017.

McKeand S.E., Mullin T.J., Byram T., and White T. 2003. Deployment of genetically improved loblolly and slash pines in the South. J. For. 101(3): 32-37.

Megraw R.A., 1985. Wood quality factors in loblolly pine. The influence of tree age, position in tree, and cultural practice on wood specific gravity, fiber length and fibril angle. Tappi Press, $88 \mathrm{p}$. 
Pliura P., Zhanga S.Y., Bousquet J., and MacKay J. 2006. Age trends in genotypic variation of wood density and its intra-ring components in young poplar hybrid crosses. Ann. For. Sci. 63: 673-685.

SAS Institute Inc., 1996. SAS/STAT Software: changes and enhancements (through release 6.11). SAS Institute Inc., Cary, N.C.

Sprague J.R., Talbert J.T., Jett J.B., and Bryant R.L., 1983. Utility of the Pilodyn in selection for mature wood specific gravity in loblolly pine. For. Sci. 29: 696-701.

Talbert J.T., Jett J.B., and Bryant R.L., 1983. Inheritance of wood specific gravity in an unimproved loblolly pine population: 20 years of results. Silvae Genet. 32: 33-37.

Tauer C.G. and Loo-Dinkins J.A., 1990. Seed source variation in specific gravity of loblolly pine grown in a common-garden experiment in Arkansas. For. Sci. 36: 1133-1145.

Wolfinger R.D., Gibson G., Wolfinger E.D., Bennett L., Hamadeh H., Bushel P., Afshari C., and Aules R.S., 2001. Assessing gene significance from cDNA Microarray expression data via mixed models. J. Comp. Biol 8: 625-637.

Wu H.X., Powell M.B., Yang J.L., Ivkovic M., and McRae T.A. 2007. Efficiency of early selection for rotation-aged wood quality traits in radiata pine. Ann. For. Sci. 64: 1-9.

Xiang B. and Li B., 2001. A new mixed analytical method for genetic analysis of diallel data. Can. J. For. Res. 31: 2252-2259.

Xiang B., Li B., and Isik F., 2003. Time trend of genetic parameter estimates in growth traits of Pinus taeda L. Silvae Genet. 52: 114-121.

Zobel B.J. and van Buijtenen J.P., 1989. Wood variation, its causes and control. Springer Verlag, Berlin, 363 p.

Zobel B.J. and Sprague J.R., 1998. Juvenile wood in forest trees. Springer Verlag, Berlin 300 p.

Zobel B.J. and Talbert J.T., 1984. Applied forest tree improvement. John Wiley \& Sons, New York. 505 pp. 
Appendix 1. A diagram depicting how elite parents were selected for wood density assessment in the Northern 1 testing region. Similar procedures were applied to other testing regions.

680 parents were mated in 130 diallels, 12 parents in a diallel group

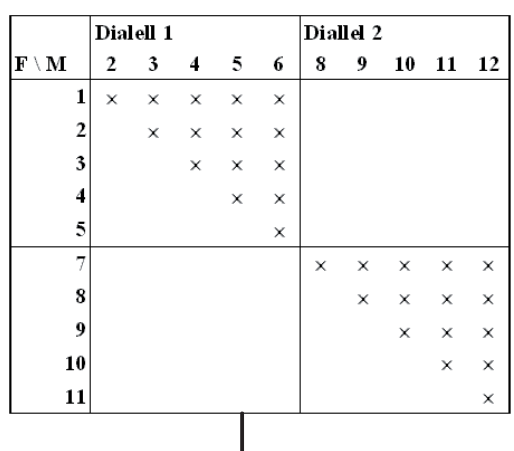

30 full-sib families + seed orchard mix checklot (SOM1) were tested at four sites

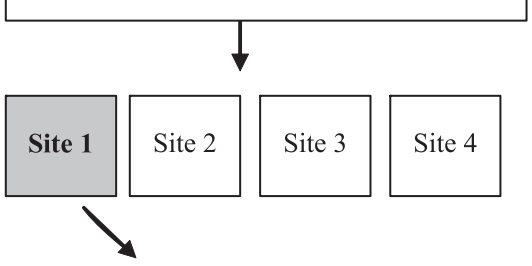

3 elite parents were selected from Diallel 1. No selection from Diallel 2.

For each parent, 15 trees were sampled from Site 1 only

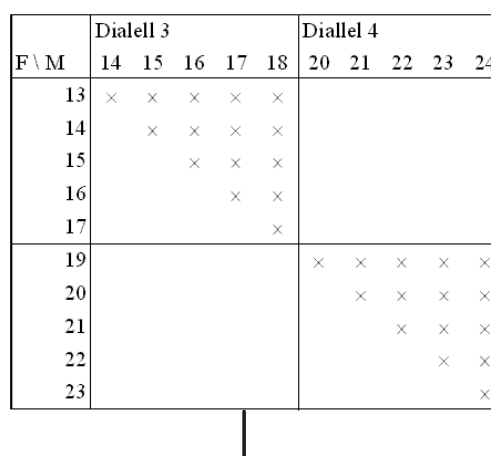

30 full-sib families + seed orchard mix checklot (SOM1) were tested at four sites

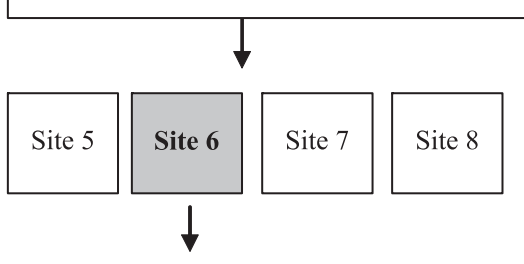

6 elite parents were selected from Diallels 3 and 4.

For each parent, 15 trees were sampled from Site 6 only

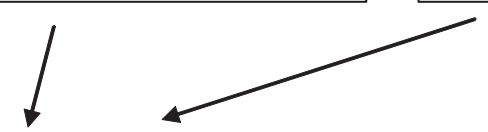

\section{More}

Diallels

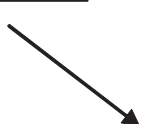

All together 20 elite parents were selected from 14 diallels for wood density study.

- 10 trees of checklot SOM1 were also sampled from each site and used as a reference sample to normalize data across 8 sites.

- Mixed model was fit to normalized data to predict wood density breeding values of parents 